\title{
Impact of obesity on rates of successful vaginal delivery after term induction of labor
}

\author{
Ivy Lin, BS, ${ }^{1}$ Abbey J. Hardy-Fairbanks, MD ${ }^{2}$
}

Keywords: Morbid obesity, induction of labor, vaginal delivery, neonatal outcome

\begin{abstract}
Objective: Determine success of term inductions of labor among an obese patient population.

Methods: A retrospective chart review of all women greater than 37 weeks gestation who underwent induction of labor at University of lowa Hospital and Clinics (12-2012 to 03-2013). Chart abstraction included data from the patient's prenatal care, medical history, labor history, delivery and postpartum course. Subjects were stratified by pre-pregnancy BMI.
\end{abstract}

Results: 74 inductions occurred at greater than 37 weeks gestation during the study period. Successful vaginal delivery (operative and spontaneous) occurred for $80.4 \%$ of normal weight women versus $82.6 \%$ for women who were obese pre-pregnancy $(p=0.85)$. Induction of obese women was associated with significantly longer infant admission (2.82 days vs 6.09 days, $p=0.03$ ) and a higher likelihood to be admitted to neonatal intensive care $(5.88 \%$ vs $26.09 \%, p=.021$ ).

Conclusions: While rates of successful vaginal delivery following induction were similar between normal weight and obese women, infants of obese women were more likely to require admission to neonatal intensive care and require longer hospital stays.

${ }^{1}$ University of lowa Carver College of Medicine, lowa City, lowa

${ }^{2}$ University of lowa Hospitals and Clinics, Department of Obstetrics and Gynecology, lowa City, lowa

\section{Introduction}

Obesity is a growing epidemic facing healthcare in the United States. More than one-third of all adults are obese (Body Mass Index or BMI $\geq 30$ ), with $6 \%$ of the population classified as extremely obese $(\mathrm{BMI} \geq 40)^{1}$ For one-third of women of childbearing age, obesity will complicate pregnancy. Obese women face higher rates of gestational diabetes mellitus and therefore macrosomic babies, an increased risk of preeclampsia and hypertension, as well as higher rates of post-term pregnancy. ${ }^{2-4}$ For these reasons, obese

Please cite this paper as: Lin I, Hardy-Fairbanks AJ. Impact of obesity on rates of successful vaginal delivery after term induction of labor. . Proceedings in Obstetrics and Gynecology, 2015;5(2):Article 4 [ 5 p.]. Available from: http://ir.uiowa.edu/pog/ Free full text article.

Corresponding author: Abbey J. Hardy-Fairbanks, MD, Department of Obstetrics and Gynecology, University of lowa Hospitals and Clinics, 200 Hawkins Drive, lowa City, IA 52242. Phone: 319-356-2291, abbey-hardyfairbanks@uiowa.edu.

Financial Disclosure: The authors report no conflict of interest.

Copyright: (c) 2015 Lin et al. This is an open-access article distributed under the terms of the Creative Commons Attribution License, which permits unrestricted use, distribution, and reproduction in any medium, provided the original author and source are credited. 
pregnant women are more likely to have a medical indication for delivery prior to spontaneous labor. ${ }^{5}$ Thus, obese women are more likely to undergo induction of labor. However, induction of labor is not without risks and added complications in any parturient, but particularly in obese women. Inductions in obese patients are known to require higher oxytocin requirements, longer labor length, as well as significantly higher cesarean delivery rates. ${ }^{6}$ Obese women are more likely to experience slower progress during labor and delivery and maternal and fetal distress, at times necessitating an emergency caesarean section. It has been reported that women with class III obesity (BMI $\geq$ 40) have a failed induction rate of $29 \%{ }^{7}$ However, the specific rate and impact of failed inductions across the obese population remains unclear posing difficulties to clinicians on how best to counsel their obese patients of term gestation.

The purpose of this study is to determine the rate of failed induction among obese patients as stratified by their pre-pregnancy BMI. Although cesarean delivery may offer a more predictable alternative to induction of labor for the obese parturient, it comes with a significant risk of maternal morbidity and mortality. ${ }^{8-10}$ Information about the success of induction of labor would offer providers improved ability to counsel obese women about their options for delivery.

\section{Methods}

This study was a retrospective chart review of all inductions of labor for women greater than 37 weeks gestation occurring at University of lowa Hospital and Clinics between December 2012 and March 2013 based on procedural billing codes. IRB approval was acquired for all study activities. The medical charts of qualified patients were reviewed for demographics, past medical history, prenatal care complications, labor, delivery, and postpartum course. Neonates were also investigated for nursery of admission and days spent in neonatal intensive care unit, if any. Study data were collected and managed using REDCap electronic data capture tools hosted by the University of lowa. ${ }^{11}$ REDCap (Research Electronic Data Capture) is a secure, web-based application designed to support data capture for research studies.

The primary outcome was defined as successful vaginal delivery; spontaneous or operative (assisted forceps or vacuum). Secondary outcomes included the length of induction, rate of chorioamnionitis, and re-admission within first six weeks postpartum. Obesity was defined as a BMI $\geq 30$ pre-pregnancy. Statistical analysis used SAS statistical software. Demographic data was compared using the Student's t-test and the Chi-square test. Outcome data was analyzed using univariate analysis to assess impact of $\mathrm{BMI}$ on successful vaginal delivery after induction.

\section{Results}

102 inductions occurred during the study period with 74 patients undergoing induction at greater than 37 weeks gestation. $31.8 \%$ were obese (BMI > 30), including 12 women who fit criteria for morbid obesity class III (BMI > 40). Age, race, number of prior vaginal deliveries and rate of neuroaxial analgesia were not significantly different 
between the non-obese and obese populations. Obese women were significantly more likely to use tobacco in pregnancy $(1.96 \%$ vs $17.39 \%$, $\mathrm{p}=0.03$ ) and to be African American or Hispanic (Table 1).

Table 1. Demographic data

\begin{tabular}{|lccc|}
\hline Demographic & $\begin{array}{c}\text { Non-Obese } \\
\text { Pre-pregnancy BMI <30 }\end{array}$ & $\begin{array}{c}\text { Obese } \\
\text { Pre-pregnancy BMI } \geq \mathbf{3 0}\end{array}$ & P-value \\
\hline Age (years) & 28.70 & 30.43 & 0.22 \\
\hline $\begin{array}{l}\text { Prior vaginal deliveries } \\
\text { (operative and spontaneous) }\end{array}$ & 0.76 & 1.09 & 0.29 \\
$\begin{array}{l}\text { Cervical dilation at start of } \\
\text { induction }\end{array}$ & 1.90 & 1.98 & 0.82 \\
\hline $\begin{array}{l}\text { Neuroaxial analgesia during } \\
\text { labor }\end{array}$ & $68.6 \%$ & $65.2 \%$ & 0.773 \\
\hline Tobacco use & $1.96 \%$ & $17.39 \%$ & 0.03 \\
\hline
\end{tabular}

The total rate of successful induction of labor resulting in a vaginal delivery (spontaneous and operative) was 81.1 $\%$ for the entire cohort. For those who were normal weight pre-pregnancy, the success was $80.39 \%$ versus $82.61 \%$ for women who were obese pre-pregnancy $(p=0.85)$, which was not significantly different. Interestingly, in this cohort, all 12 women with class III obesity (BMI $>40$ ) delivered via spontaneous vaginal delivery. There was no significant difference when the population of women with BMI greater than 30 were divided into those with BMI between 3040 and those with BMI >40 (Table 2).

\section{Table 2. Primary outcomes}

\begin{tabular}{|c|c|c|c|c|}
\hline Mode of delivery & $\begin{array}{c}\text { Non-Obese } \\
\text { Pre-pregnancy } \\
\text { BMI }<30\end{array}$ & \multicolumn{2}{|c|}{$\begin{array}{c}\text { Obese } \\
\text { Pre-pregnancy BMI } \geq 30\end{array}$} & P-value \\
\hline \multirow[t]{2}{*}{$\begin{array}{l}\text { Vaginal delivery } \\
\text { (spontaneous and operative) }\end{array}$} & $80.39 \%$ & \multicolumn{2}{|c|}{$82.61 \%$} & 0.85 \\
\hline & BMI $<30$ & BMI $30-40$ & \multicolumn{2}{|c|}{$\mathrm{BMI}>40$} \\
\hline $\begin{array}{l}\text { Vaginal delivery } \\
\text { (spontaneous and operative) }\end{array}$ & $80.39 \%$ & $63.64 \%$ & $100 \%$ & $\begin{array}{l}0.41(\text { BMI }<30: 30-40) \\
0.20(\text { BMI } 30-40:>40) \\
0.08(\text { BMI }<30:>40)\end{array}$ \\
\hline
\end{tabular}

Review of secondary outcomes (Table 3) showed that induction of obese women was associated with a significantly longer infant admission (2.82 days vs 6.09 days, $p=0.03$ ). Although not significant, infants of obese women were 5.75 times more likely to be admitted to the neonatal intensive care unit than the infants of non-obese women $(p=0.059)$. In addition, obese patients required more doses of misoprostol $25 \mathrm{mcg}$ (3.11 vs. 1.96; $\mathrm{p}=0.03)$ and dinoprostone $10 \mathrm{mg}(1.43$ vs. $1.06 ; p=0.03$ ) for induction. There 
Proceedings in Obstetrics and Gynecology, 2015;5(2):4

was no significant difference in infant weights, rate of chorioamnionitis or re-

admission in the postpartum period.

Table 3. Secondary outcomes

\begin{tabular}{|lccc|}
\hline Outcome & $\begin{array}{c}\text { Non-Obese } \\
\text { Pre-pregnancy BMI }<30\end{array}$ & $\begin{array}{c}\text { Obese } \\
\text { Pre-pregnancy BMI } \geq 30\end{array}$ & P-value \\
\hline Infant admission to the NICU & $5.88 \%$ & $26.09 \%$ & 0.02 \\
\hline Infant weight (grams) & 3951.7 & 3436.1 & 0.58 \\
\hline Length of infant admission (days) & 2.82 & 6.09 & 0.03 \\
\hline Pediatrics present at delivery & $60.8 \%$ & $69.6 \%$ & 0.46 \\
\hline Chorioamnionitis & $17.7 \%$ & $14.0 \%$ & 0.74 \\
\hline Doses of misoprostol 25mcg & 1.96 & 3.11 & 0.03 \\
\hline Doses of dinoprostone 10mg & 1.06 & 1.43 & 0.03 \\
\hline Meconium present & 17.65 & 30.43 & 0.23 \\
\hline Estimated blood loss (mL) & 528.0 & 503.4 & 0.78 \\
\hline Length of ruptured membranes (min) & 376.4 & 417.3 & 0.64 \\
\hline
\end{tabular}

\section{Discussion}

We hypothesized that obese patients would have a higher rate of inductions resulting in cesarean delivery due to increased risk of complications within this population. Our study did not show any significant statistical difference in failure of inductions between the obese and non-obese population. These early results may suggest that induction at term for obese patients is a reasonable course of action rather than primary caesarian section if delivery is indicated before the start of spontaneous labor. Of note, obese women were more likely to require more doses of induction agents. The lack of a statistical difference could be attributed to the small size of this initial study. Also of note, the twelve patients included in this study with class III obesity (BMI greater than 40) all delivered via spontaneous vaginal delivery contradicting previously reported decreased successful vaginal delivery rates after induction in this patient population. ${ }^{7}$ Again, this may also be due to our small sample size.

Our study did find a correlation between obese pregnant women and increased lengths of infant hospital stay and NICU admissions, despite similar rates of medical and pregnancy related comorbidities. The infants of obese mothers in this study required on average six days in the hospital. This is more than double the average length of hospital stay for their counterparts of non-obese mothers. Although this negative impact of maternal obesity for neonates at birth is concerning, further investigation into the long term impact of maternal obesity on infants is needed. Along with the health impacts of maternal obesity on the baby, this also implies a dramatically greater hospital fee and larger healthcare allocation dedicated to these infants.

Our preliminary efforts indicate induction as a reasonable course of action for 
obese patients, particularly with the known increased risks of cesarean delivery in this population (infection, wound dehiscence, venous thromboembolism, among others). ${ }^{8,10}$ However, the infants of obese patients typically require longer hospital and have higher rates NICU admission.

\section{References}

1. Ogden CL, Carroll MD, Flegal KM. Prevalence of obesity in the United States. JAMA. 2014 Jul;312(2):189-90. doi: 10.1001/jama.2014.6228. PubMed PMID: 25005661.

2. Baeten JM, Bukusi EA, Lambe M. Pregnancy complications and outcomes among overweight and obese nulliparous women. Am J Public Health. 2001 Mar;91(3):436-40. doi: 10.2105/AJPH.91.3.436 PubMed PMID: 11236410.

3. Cedergren MI. Maternal morbid obesity and the risk of adverse pregnancy outcome. Obstet Gynecol. 2004 Feb;103(2):219-24. http://dx.doi.org/10.1097/01.AOG.00001 07291.46159.00 PubMed PMID: 14754687.

4. Sebire NJ, Jolly $M$, Harris JP, Wadsworth J, Joffe M, Beard RW, Regan L, Robinson S. Maternal obesity and pregnancy outcome: a study of 287,213 pregnancies in London. Int $\mathrm{J}$ Obes Relat Metab Disord. 2001 Aug;25(8):1175-82. http://dx.doi.org/10.1038/sj.ijo.0801670 PubMed PMID: 11477502.

5. Weiss JL, Malone FD, Emig D, Ball RH, Nyberg DA, Comstock CH, Saade G, Eddleman K, Carter SM, Craigo SD, Carr SR, D'Alton ME; FASTER Research Consortium. Obesity, obstetric complications and cesarean delivery rate-a population-based screening study. Am J Obstet Gynecol. 2004 Apr;190(4):1091-7. http://dx.doi.org/10.1016/j.ajog.2003.09. 058 PubMed PMID: 15118648.
6. Pevzner L, Powers BL, Rayburn WF, Rumney $P$, Wing DA. Effects of maternal obesity on duration and outcomes of prostaglandin cervical ripening and labor induction. Obstet Gynecol. 2009 Dec;114(6):1315-21. doi: 10.1097/AOG.0b013e3181bfb39f.

PubMed PMID: 19935035.

7. Wolfe KB, Rossi RA, Warshak CR. The effect of maternal obesity on the rate of failed induction of labor. Am J Obstet Gynecol. 2011 Aug;205(2):128.e1-7. doi: 10.1016/j.ajog.2011.03.051. Epub 2011 Apr 8. PubMed PMID: 21621187.

8. Myles TD, Gooch J, Santolaya J. Obesity as an independent risk factor for infectious morbidity in patients who undergo cesarean delivery. Obstet Gynecol. 2002 Nov;100(5 Pt 1):959-64. http://dx.doi.org/10.1016/S00297844(02)02323-2 PubMed PMID: 12423861.

9. Perlow JH, Morgan MA. Massive maternal obesity and perioperative cesarean morbidity. Am J Obstet Gynecol. $1994 \quad$ Feb;170(2):560-5. http://dx.doi.org/10.1016/S00029378(94)70227-6 PubMed PMID: 8116713.

10. Cetin A, Cetin M. Superficial wound disruption after cesarean delivery: effect of the depth and closure of subcutaneous tissue. Int J Gynaecol Obstet. $1997 \quad$ Apr;57(1):17-21. http://dx.doi.org/10.1016/S00207292(97)02836-1 PubMed PMID: 9175664.

11. Harris PA, Taylor R, Thielke R, Payne J, Gonzalez N, Conde JG. Research electronic data capture (REDCap)--a metadata-driven methodology and workflow process for providing translational research informatics support. J Biomed Inform. 2009 Apr;42(2):377-81. doi: 10.1016/j.jbi.2008.08.010. Epub 2008 Sep 30. PubMed PMID: 18929686. 